\title{
Interleukin-8: A potent promoter of human lymphatic endothelial cell growth in gastric cancer
}

\author{
JUN SHI, YONG-JIN LI, BING YAN and PIN-KANG WEI \\ Department of Traditional Chinese Medicine, Shanghai Changzheng Hospital, \\ The Second Military Medical University, Shanghai, P.R. China \\ Received January 5, 2015; Accepted March 26, 2015
}

DOI: $10.3892 /$ or.2015.3916

\begin{abstract}
Lymphatic metastasis is a major progression route of gastric cancer. Interleukin-8 (IL-8), as an inflammatory cytokine, is induced by Helicobacter pylori infection and is strongly associated with gastric cancer development and metastasis. The blood and lymphatic systems are similar in their function and gene expression profiles. It has been proposed that IL-8 activates angiogenesis. However, the direct role of IL-8 in lymphangiogenesis in gastric cancer remains unclear. We investigated the effect of IL-8 on the growth of human lymphatic endothelial cells (LECs). In addition, protein and mRNA expression of selected lymphangiogenesis markers was assessed in these cells. LECs were co-cultured with gastric cancer SGC7901 cells and exposed to various concentrations of IL-8 $(0,0.2,0.5,0.8$ and $1.0 \mathrm{ng} / \mathrm{ml})$. The Cell Counting Kit-8 was used to evaluate LEC proliferation (cultured for 1-6 days). Then, protein (immunofluorescence and western blotting) and mRNA [quantitative transcription-polymerase chain reaction (qPCR)] levels were measured in samples obtained from the 24-h cultured cells, for lymphatic vessel endothelial hyaluronic acid receptor-1 (LYVE-1), vascular endothelial growth factor (VEGF)-C, VEGF-D and vascular endothelial growth factor receptor-3 (VEGFR-3). The data presented herein demonstrated that IL-8 promotes the proliferation of LECs and enhances the protein and mRNA expression of LYVE-1. Notably, IL-8 inhibited VEGF-C, VEGF-D and VEGFR-3 protein expression as well as VEGF-D and VEGFR-3 mRNA expression. These findings suggest that IL- 8 may be a potent inducer of LECs, although this effect does not appear to involve the VEGF-C/VEGF-D and VEGFR-3 signaling pathway.
\end{abstract}

Correspondence to: Professor Pin-Kang Wei or Dr Jun Shi, Department of Traditional Chinese Medicine, Shanghai Changzheng Hospital, The Second Military Medical University, 415 Fengyang Road, Huangpu Avenue, Shanghai, P.R. China

E-mail: czzyk73408@163.com

E-mail: shijundoctor@163.com

Key words: interleukin-8, lymphangiogenesis, gastric cancer, lymphatic vessel endothelial hyaluronic acid receptor 1, lymphangiogenic growth factor

\section{Introduction}

Gastric cancer is the leading cause of death from gastrointestinal malignancy and is associated with Helicobacter pylori (Hp) infection. Higher levels of interleukin-8 (IL-8), a CXC chemokine, have been shown in $\mathrm{Hp}$-infected gastric tissues in comparison with Hp-negative tissues (1). Meanwhile, upregulation of IL-8 was observed in gastric cancer (2), and IL-8 plays an important role in adhesion, migration and invasion of gastric cancer cells (3). Hence, overexpression of IL-8 is associated with the development and metastasis of gastric cancer (4).

Gastric cancer patients (50-75\%) are diagnosed at stages III or IV with lymphatic metastasis (5), which is considered the strongest prognostic factor regarding long-term survival in gastric cancer. Lymphangiogenesis, the formation of lymphatic vessels, is linked to lymphatic metastasis and plays an important role in malignant cell dissemination. The growth of lymphatic endothelial cells (LECs) is regarded as the fundamental step of lymphangiogenesis. The blood and lymphatic systems as the two major circulatory systems in humans are similar in their function and anatomy. Moreover, the endothelial cells from blood and lymphatic vessels display similar gene expression profiles; many growth factors and various inflammatory mediators were shown to activate both angiogenesis and lymphangiogenesis (6-8). Notably, the inflammatory cytokine IL-8 has been shown to activate angiogenesis $(9,10)$. However, the direct role of IL- 8 in gastric cancer lymphangiogenesis is poorly understood. Furthermore, the recent identification of lymphatic endothelial-specific markers has greatly increased attention to the regulation of lymphangiogenesis in the cancer microenvironment. It has been reported that vascular endothelial growth factor (VEGF)-C and VEGF-D both bind their receptor, vascular endothelial growth factor receptor-3 (VEGFR-3), and VEGF signaling is involved in the development and growth of the lymphatic system (11). It has been shown that secretion of VEGF-C and VEGF-D by some tumors induces VEGFR-3 activation in the vascular endothelium, thereby promoting the formation of new lymphatic vessels (12). Whether VEGF signaling is involved in IL-8-induced lymphangiogenesis in gastric cancer is still unclear. In the present study, we evaluated the effect of IL- 8 on the growth of LECs and expression of VEGF-C, VEGF-D and VEGFR-3, using a co-culture model including gastric cancer SGC7901 cells and LECs. 


\section{Materials and methods}

Cell culture. The human gastric cancer SGC7901 and human lymphatic endothelial cells were purchased from the Cell Bank of the Chinese Academy of Sciences (Shanghai, China) and ScienCell Research Laboratories (Carlsbad, CA, USA), respectively. All cells were cultured in endothelial cell medium (ScienCell), supplemented with 5\% fetal bovine serum (FBS; Zhejiang Tianhang Biological Technology Co., Ltd., Hangzhou, China), $1 \%$ penicillin/streptomycin and $1 \%$ endothelial cell growth supplement (ScienCell). Cells were maintained at $37^{\circ} \mathrm{C}$ in a humidified chamber containing $5 \%$ $\mathrm{CO}_{2}$.

Co-culture model, cell grouping and IL-8 treatment. SGC7901 cells $\left(2 \times 10^{5}\right.$ cells/well) were cultured for $24 \mathrm{~h}$ with an IL-8 stock solution (Sigma-Aldrich, St. Louis, MO, USA) added to a predetermined concentration. Then, SGC7901 cell culture media were collected and added to LECs for further incubation. Based on culture media and IL- 8 doses, 6 groups were established experimentally: control group (only endothelial cell medium without SGC7901 cell culture medium) and 5 IL-8 groups with SGC7901 cell culture media containing various concentrations of the cytokine $(0,0.2,0.5,0.8$ and $1 \mathrm{ng} / \mathrm{ml}$ groups).

Cell proliferation assay. Cell proliferation was assessed using a Cell Counting Kit-8 (CCK-8; Dojindo, Kunamoto, Japan), according to the manufacturer's instructions. Briefly, LECs $\left(2 \times 10^{3}\right.$ cells/well) in logarithmic phase were cultured in 96-well plates and incubated overnight to allow adherence. After washing, various culture media (see cell grouping above) were added to the LECs, followed by 1-6 days of incubation. There were 9 replicate wells for each group. At each time point, $10 \mu \mathrm{lWST}-8$, which produces a water-soluble formazan, was diluted in $100 \mu \mathrm{l}$ endothelial cell medium and added to the LECs. After an additional $3 \mathrm{~h}$ incubation of the LECs, absorbance was measured by a microplate reader (Multiskan MK3; Thermo Fisher, Waltham, MA, USA) at $450 \mathrm{~nm}$ to obtain an optical density $(\mathrm{OD})$ value. $\mathrm{OD}$ ultimate value $=\mathrm{OD}$ measured value - OD blank value.

Immunofluorescence staining. LECs $\left(5 \times 10^{4}\right)$ were seeded on coverslips in 24-well plates and cultured with endothelial cell medium at $37^{\circ} \mathrm{C}$ to allow adherence. Then LECs were cultured in the presence of various culture media containing different IL-8 concentrations for $24 \mathrm{~h}$. After fixation in $4 \%$ paraformaldehyde for $15 \mathrm{~min}$, sequential treatments with $0.5 \%$ Triton $\mathrm{X}-100$ for $10 \mathrm{~min}$ and $4 \%$ bovine serum albumin (BSA) for $1 \mathrm{~h}$ at room temperature, LECs were incubated with lymphatic vessel endothelial hyaluronic acid receptor-1 (LYVE-1) rabbit polyclonal antibody (1:50), VEGF-C goat polyclonal antibody (1:80) (both from Santa Cruz Biotechnology, Santa Cruz, CA, USA), VEGF-D rabbit monoclonal antibody (1:100; Epitomics, Burlingame, CA, USA), VEGFR-3 rabbit polyclonal antibody (1:100; Abcam, Cambridge, UK), respectively, at $4^{\circ} \mathrm{C}$ overnight. Afterwards, Cy3-conjugated Affinipure goat anti-rabbit IgG $(\mathrm{H}+\mathrm{L})(1: 1,000$ dilution) and $\mathrm{Cy} 3$-conjugated Affinipure donkey anti-goat IgG $(\mathrm{H}+\mathrm{L})(1: 1,000$ dilution) (both from Proteintech Group,
Table I. Sequences of the primers used for qPCR

\begin{tabular}{lll}
\hline mRNA & \multicolumn{1}{c}{ Sense primer sequence } & bp \\
\hline hGAPDH-F & 5'-GGGTGTGAACCATGAGAAGTATG-3' & 145 \\
hGAPDH-R & 5'-GATGGCATGGACTGTGGTCAT-3' & \\
LYVE-1-F & 5'-ATCCCCTTACTCTACAATACCTGC-3' & 262 \\
LYVE-1-R & 5'-GACATAGCAAAATCCAAGACCAG-3' & \\
VEGF-C-F & 5'-GCTGGAGATGACTCAACAGATGG-3' & 243 \\
VEGF-C-R & 5'-GGGGCAGGTTCTTTTACATACAC-3' & \\
VEGF-D-F & 5'-CATCCCATCGGTCCACTAGG-3' & 189 \\
VEGF-D-R & 5'-AGCCACCACATCGGAACAC-3' & \\
VEGFR-3-F & 5'-TCATCGCTGTCTTCTTCTGGG-3' & 141 \\
VEGFR-3-R & 5'-GGTATTCGCATTGCTCCTCC-3' & \\
\hline & & \\
LYVE-1, lymphatic vessel endothelial hyaluronic acid receptor-1; \\
VEGF-C, vascular endothelial growth factor-C; VEGF-D, vascular \\
endothelial growth factor-D; VEGFR-3, vascular endothelial growth \\
factor receptor-3.
\end{tabular}

Wuhan, China) were added to the corresponding samples for an additional $1 \mathrm{~h}$. After counterstaining with DAPI, coverslips were observed under a laser confocal scanning microscope (LSM710; Zeiss, Oberkochen, Germany).

Western blot analysis. LECs $\left(2 \times 10^{5}\right)$ were incubated for $24 \mathrm{~h}$, collected and lysed in $150 \mu 1$ cell lysate buffer. Cell lysates were centrifuged for $1 \mathrm{~min}$ at $12,000 \mathrm{rpm}$, and the supernatants were collected, boiled in sample buffer for $10 \mathrm{~min}$ at $100^{\circ} \mathrm{C}$ and separated by SDS-PAGE (10\% separation gel, 5\% spacer gel). After electrotransfer onto polyvinylidene difluoride film (Bio-Rad, Hercules, CA, USA), the membranes were blocked for $1 \mathrm{~h}$ at room temperature. Then, LYVE-1 rabbit polyclonal antibody (1:250), VEGF-C goat polyclonal antibody (1:250), VEGF-D rabbit monoclonal antibody (1:250), VEGFR-3 rabbit polyclonal antibody (1:250) and GAPDH mouse monoclonal antibody (1:3,000; Sungene, Tianjin, China) were used to probe the blots overnight at $4^{\circ} \mathrm{C}$. After a washing step, the membranes were incubated with anti-rabbit IgG-HRP $(1: 1,000)$, anti-mouse IgG-HRP $(1: 3,000)$ and antigoat IgG-HRP $(1: 1,000)$ secondary antibodies, respectively, for $1 \mathrm{~h}$ at room temperature. The membranes were washed and detection was carried out using a SuperSignal West Pico Chemiluminescent Substrate kit (Thermo Fisher Scientific). Finally, the membranes were exposed to X-ray film in a darkroom and scanned by an image analyzer. Grayscale analysis was performed by ImageJ software, and LYVE-1, VEGF-C, VEGF-D and VEGFR-3 levels were assessed, relative to GAPDH (internal control). The rates of the 5 experimental groups were normalized to the control group (values set at 1) and considered protein levels. All experiments were repeated three times.

Quantitative transcription-polymerase chain reaction (qPCR) analysis. LECs were seeded in 12-well plates at a density of $7 \times 10^{4}$ cells/well and incubated for $24 \mathrm{~h}$. Total RNA was extracted from the LECs using TRIzol reagent (Takara, Shiga, Japan) and reverse transcribed with the RevertAid 


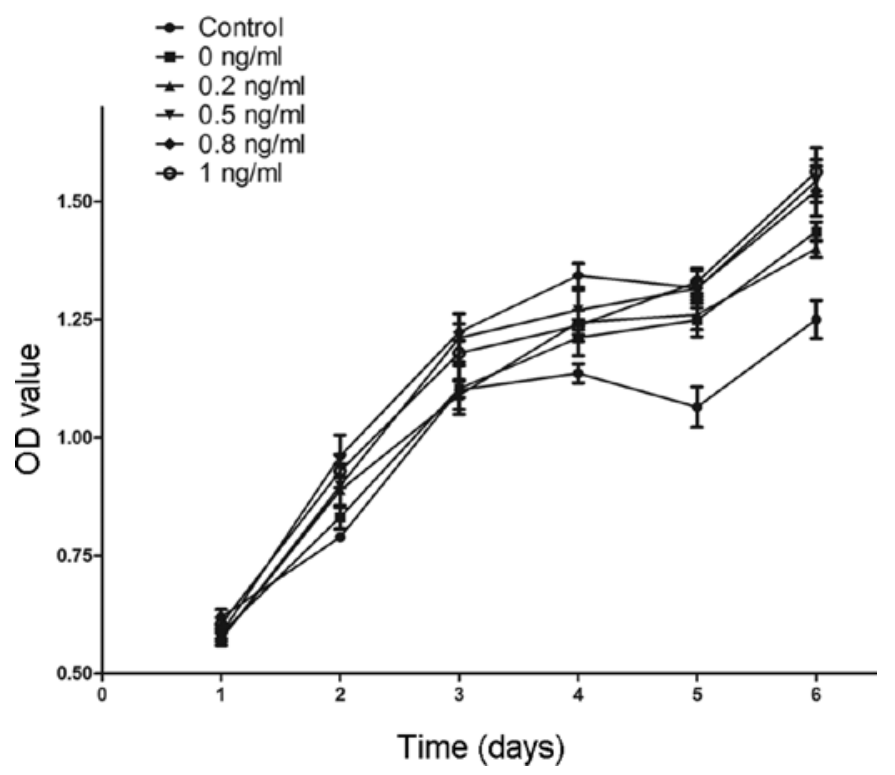

Figure 1. IL-8 promotes proliferation of LECs. From the first to the sixth day, OD values increased gradually. Cell proliferation was significantly different at various time points $(\mathrm{P}<0.05)$, and an interaction was found between time factor and intervention $(\mathrm{P}<0.05)$. Growth of the $0 \mathrm{ng} / \mathrm{ml}$ group cultured with pure SGC7901 cell culture medium was faster than that of the control group $(\mathrm{P}<0.05)$. Meanwhile, OD values obtained for the $0.5,0.8$ and $1.0 \mathrm{ng} / \mathrm{ml}$ groups were significantly higher when compared with the OD value of the $0 \mathrm{ng} / \mathrm{ml}$ group $(\mathrm{P} \leq 0.001)$. IL-8, interleukin-8; LECs, lymphatic endothelial cells; OD, optical density.

Reverse Transcriptase (Thermo Fisher Scientific), according to the manufacturer's instructions. Quantitative RT-PCR was performed with SYBR-Green chemistry on a Bio-Rad iQ5 Real-Time PCR system (Bio-Rad), with each sample analyzed in triplicate. The reaction conditions consisted of one cycle of $95^{\circ} \mathrm{C}$ for $2 \mathrm{~min}, 95^{\circ} \mathrm{C}$ for $15 \mathrm{sec}, 60^{\circ} \mathrm{C}$ for $20 \mathrm{sec}, 72^{\circ} \mathrm{C}$ for $20 \mathrm{sec}$ and then $40 \mathrm{cycles}$ of $72^{\circ} \mathrm{C}$ for $30 \mathrm{sec}$. Relative levels of LYVE-1, VEGF-C, VEGF-D and VEGFR-3 mRNA expression were normalized to GAPDH mRNA expression, and calculated by the $2^{-\Delta \Delta \mathrm{Ct}}$ method. The primer sequences for each gene analyzed are summarized in Table I.

Statistical methods. The resulting measurements were expressed as mean \pm standard deviation (SD) for each data point. All data were analyzed using the SPSS 13.0 soft- ware. ANOVA for repeated measurement data was used to determine statistical significance of differences in the cell proliferation experiments. One-way ANOVA was used to assess the expression of protein or mRNA. The LSD method was used to analyze post-hoc multiple comparisons. All reported P-values were two-sided with a statistical significance level of $<0.05$.

\section{Results}

IL-8 promotes the proliferation of human LECs. We investigated the effect of IL-8 on LEC proliferation using the CCK-8 kit. Our data showed a significant difference in the proliferation of cells between interventions and days. Pure SGC7901 cell culture medium promoted proliferation of the LECs. Notably, IL-8 at concentrations $>0.5 \mathrm{ng} / \mathrm{ml}$ potently induced LEC growth (Table II, Fig. 1).

IL-8 promotes $L Y V E-1$ protein and $m R N A$ expression. We next investigated the effect of IL-8 on protein and mRNA expression of LYVE-1, a marker of lymphogenesis. Pure SGC7901 cell culture medium did not alter LYVE-1 protein expression levels. However, IL-8 promoted LYVE-1 protein expression at concentrations $>0.8 \mathrm{ng} / \mathrm{ml}$ (Table III, Figs. 2 and 3).

Similar results were found for mRNA expression of LYVE-1; LYVE-1 mRNA levels were not regulated by pure SGC7901 cell culture medium and were upregulated by IL-8 concentrations $>0.5 \mathrm{ng} / \mathrm{ml}$ (Table IV, Fig. 4).

IL-8 inhibits protein and mRNA expression of VEGF-D, $V E G F-C$ and VEGFR-3. The secretion of VEGF-C and VEGF-D was reported to induce the formation of new lymphatic vessels via activation of VEGFR-3 (13). Hence, we next investigated the possible role of VEGF-C/VEGF-D and the VEGFR-3 signaling pathway in IL-8-induced LEC growth. We found that pure SGC7901 cell culture medium had an insignificant effect on VEGF-C and VEGF-D protein expression. This medium even inhibited VEGFR-3 protein expression. Notably, VEGF-C, VEGF-D and VEGFR-3 protein levels were overtly decreased after IL-8 addition (Table III, Fig. 5). Furthermore, we found that pure SGC7901 cell culture medium inhibited the expression of VEGF-D mRNA, yet enhanced VEGFR-3 gene expression. After IL-8 treatment, VEGF-D and VEGFR-3

Table II. Effect of IL-8 on LEC proliferation (OD).

\begin{tabular}{lcccccc}
\hline Group & 1st Day & 2nd Day & 3rd Day & 4th Day & 5th Day & 6th Day \\
\hline Control & $0.62 \pm 0.02$ & $0.79 \pm 0.01$ & $1.10 \pm 0.05$ & $1.14 \pm 0.02$ & $1.06 \pm 0.04$ & $1.25 \pm 0.04$ \\
$0 \mathrm{ng} / \mathrm{ml}$ & $0.59 \pm 0.02$ & $0.83 \pm 0.03$ & $1.10 \pm 0.02$ & $1.21 \pm 0.04$ & $1.25 \pm 0.04$ & $1.44 \pm 0.02$ \\
$0.2 \mathrm{ng} / \mathrm{ml}$ & $0.57 \pm 0.01$ & $0.89 \pm 0.01$ & $1.09 \pm 0.03$ & $1.24 \pm 0.03$ & $1.26 \pm 0.03$ & $1.40 \pm 0.02$ \\
$0.5 \mathrm{ng} / \mathrm{ml}$ & $0.57 \pm 0.01$ & $0.90 \pm 0.05$ & $1.21 \pm 0.05$ & $1.27 \pm 0.04$ & $1.32 \pm 0.02$ & $1.54 \pm 0.05$ \\
$0.8 \mathrm{ng} / \mathrm{ml}$ & $0.58 \pm 0.01$ & $0.96 \pm 0.04$ & $1.22 \pm 0.02$ & $1.34 \pm 0.03$ & $1.32 \pm 0.04$ & $1.52 \pm 0.05$ \\
$1.0 \mathrm{ng} / \mathrm{ml}$ & $0.60 \pm 0.01$ & $0.93 \pm 0.04$ & $1.18 \pm 0.03$ & $1.24 \pm 0.03$ & $1.33 \pm 0.02$ & $1.56 \pm 0.05$ \\
\hline
\end{tabular}

IL-8, interleukin-8; LECs, lymphatic endothelial cells; OD, optical density. 
Table III. Effect of IL-8 on LYVE-1, VEGF-D, VEGF-C and VEGFR-3 protein expression.

\begin{tabular}{lllll}
\hline Group & LYVE-1 & VEGF-D & VEGF-C & VEGFR-3 \\
\hline Control & $1.00 \pm 0.00$ & $1.00 \pm 0.00$ & $1.00 \pm 0.00$ & $1.00 \pm 0.00$ \\
$0 \mathrm{ng} / \mathrm{ml}$ & $0.99 \pm 0.03$ & $0.99 \pm 0.06$ & $1.09 \pm 0.03$ & $0.81 \pm 0.08^{\mathrm{b}}$ \\
$0.2 \mathrm{ng} / \mathrm{ml}$ & $0.98 \pm 0.06$ & $0.84 \pm 0.03^{\mathrm{c}}$ & $0.67 \pm 0.04^{\mathrm{d}}$ & $0.57 \pm 0.04^{\mathrm{d}}$ \\
$0.5 \mathrm{ng} / \mathrm{ml}$ & $1.06 \pm 0.06$ & $0.83 \pm 0.04^{\mathrm{d}}$ & $0.63 \pm 0.09^{\mathrm{d}}$ & $0.63 \pm 0.04^{\mathrm{d}}$ \\
$0.8 \mathrm{ng} / \mathrm{ml}$ & $1.14 \pm 0.03^{\mathrm{d}}$ & $0.82 \pm 0.10^{\mathrm{d}}$ & $0.50 \pm 0.07^{\mathrm{d}}$ & $0.62 \pm 0.02^{\mathrm{d}}$ \\
$1.0 \mathrm{ng} / \mathrm{ml}$ & $1.50 \pm 0.04^{\mathrm{d}}$ & $0.59 \pm 0.03^{\mathrm{d}}$ & $0.69 \pm 0.03^{\mathrm{d}}$ & $0.75 \pm 0.03$ \\
\hline
\end{tabular}

${ }^{\mathrm{a}} \mathrm{P}<0.05,{ }^{\mathrm{b}} \mathrm{P}<0.01$ vs. control group, ${ }^{\mathrm{c}} \mathrm{P}<0.05$, ${ }^{\mathrm{d}} \mathrm{P}<0.01 \mathrm{vs} .0 \mathrm{ng} / \mathrm{ml}$ group. IL-8, interleukin-8; LYVE-1, lymphatic vessel endothelial hyaluronic acid receptor-1; VEGF-D, vascular endothelial growth factor-D; VEGF-C, vascular endothelial growth factor-C; VEGFR-3, vascular endothelial growth factor receptor-3.

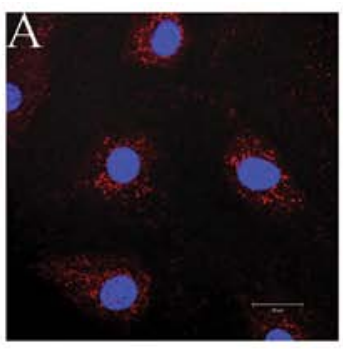

$0 \mathrm{ng} / \mathrm{ml}$

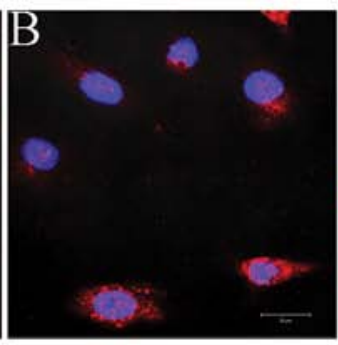

$0.2 \mathrm{ng} / \mathrm{ml}$

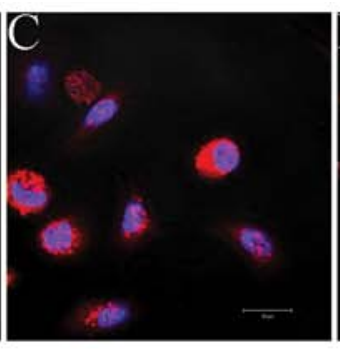

$0.5 \mathrm{ng} / \mathrm{ml}$

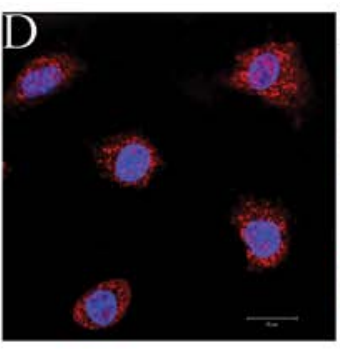

$0.8 \mathrm{ng} / \mathrm{ml}$

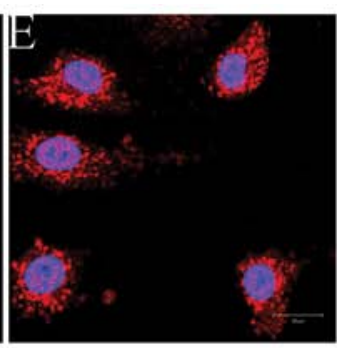

$1.0 \mathrm{ng} / \mathrm{ml}$

Figure 2. IL-8 promotes LYVE-1 protein expression in LECs (immunofluorescence staining, x630). Cell nuclei counterstained with DAPI (blue) and LYVE-1 stained with Cy3 (red). LYVE-1 protein was found on the cell membrane and in the cytoplasm. IL-8, interleukin-8; LYVE-1, lymphatic vessel endothelial hyaluronic acid receptor-1; LECs, lymphatic endothelial cells. (A) 0, (B) 0.2 , (C) 0.5 , (D) 0.8 and (E) $1.0 \mathrm{ng} / \mathrm{ml} \mathrm{group}$.

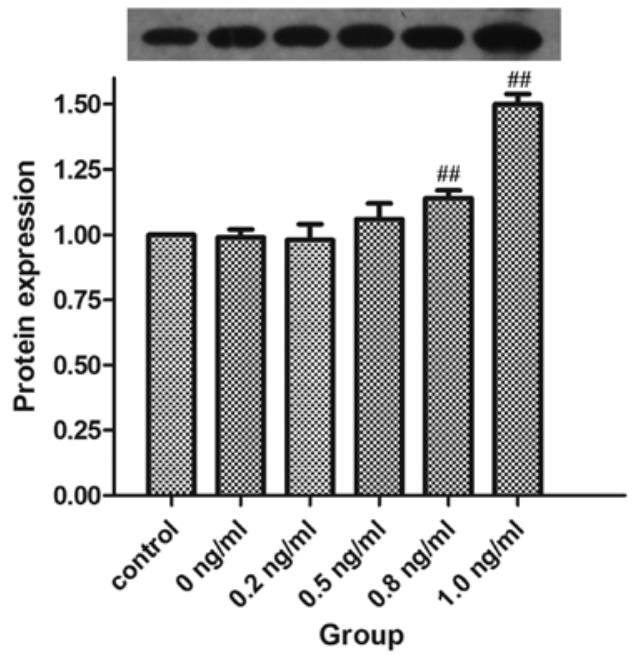

Figure 3. IL-8 promotes LYVE-1 protein expression in LECs (western blotting, $40 \mathrm{kDa}$ ). The expression levels in the $0 \mathrm{ng} / \mathrm{ml}$ group were not significantly different when compared with the values obtained for the control group $(\mathrm{P}=1.000)$. In contrast, the expression levels in 0.8 and $1.0 \mathrm{ng} / \mathrm{ml}$ groups were significantly different to that of the $0 \mathrm{ng} / \mathrm{ml}$ group $(\mathrm{P}=0.009$ and $\mathrm{P}<0.001$, respectively). ${ }^{\#} \mathrm{P}<0.01$ vs. $0 \mathrm{ng} / \mathrm{ml}$ group. IL- 8 , interleukin-8; LYVE-1, lymphatic vessel endothelial hyaluronic acid receptor-1; LECs, lymphatic endothelial cells.

mRNA expression levels were decreased, in good accordance with the protein levels described above. Neither pure SGC7901 cell culture medium nor IL-8 showed a significant effect on VEGF-C mRNA expression (Table IV, Fig. 4).

\section{Discussion}

IL-8, a member of the neutrophil-specific CXC subfamily of chemokines, has been shown to be involved in leukocyte chemotaxis, inflammatory responses and infectious diseases (14). It plays an important role in the proliferation, invasion and migration of endothelial cells $(15,16)$. Gastric cancer, the leading cause of death from gastrointestinal malignancy worldwide, is associated with Helicobacter pylori (Hp) infection $(17,18)$. Hp directly increases gastric epithelial IL-8 protein secretion and IL-8 mRNA expression $(1,19,20)$. Meanwhile, IL-8 upregulation also occurs in gastric cancer (2). Therefore, it has been suggested that IL-8, as a significant regulatory autocrine factor within the tumor microenvironment (21), is strongly associated with gastric cancer. In a previous study, we reported that recombinant IL- 8 promotes adhesion, migration and invasion of human gastric cancer SGC7901 cells (22). Using cDNA and siRNA transfectants, Kuai et al reported similar findings (3). Furthermore, a previous study showed that IL-8 overexpression is linked to invasion and metastasis in gastric cancer (4). Therefore, IL-8 is considered as an important multifunctional factor in the metastasis of gastric cancer.

The lymphatic system is a one way, open-ended complex network comprised of capillaries, trunks, ducts and lymph 
Control $0 \quad 0.2 \quad 0.5 \quad 0.8 \quad 1.0(\mathrm{ng} / \mathrm{ml})$

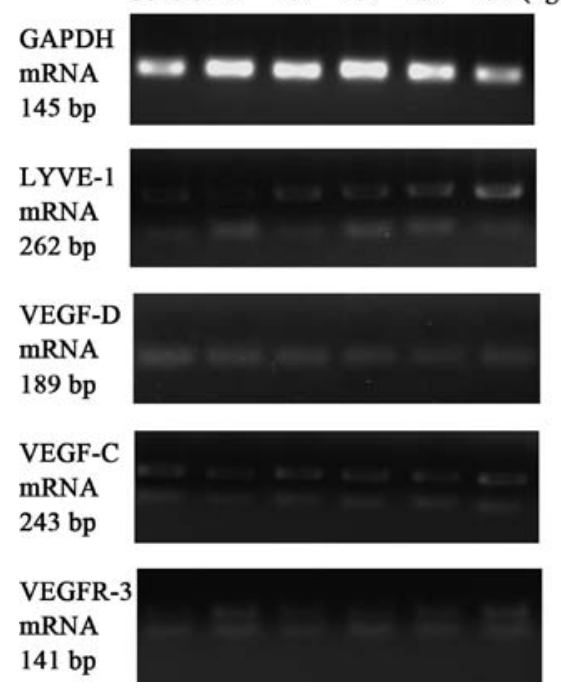

Figure 4. IL-8 inhibits VEGF-D and VEGFR-3 mRNA expression in LECs (qPCR). A non-significant difference in VEGF-C mRNA levels was found among all groups $(\mathrm{P}=0.079)$. Pure $\mathrm{SGC7901}$ cell culture medium inhibited VEGF-D mRNA expression $(\mathrm{P}<0.001)$ and promoted VEGFR-3 mRNA expression $(\mathrm{P}<0.001)$. VEGF-D mRNA expression levels in the $0.5,0.8$ and $1.0 \mathrm{ng} / \mathrm{ml}$ groups were significantly decreased compared with the $0 \mathrm{ng} / \mathrm{ml}$ group $(\mathrm{P}=0.024, \mathrm{P}<0.001$ and $\mathrm{P}=0.004$, respectively). A similar decreased expression of VEGFR-3 mRNA in the $0.2,0.5,0.8$ and $1.0 \mathrm{ng} / \mathrm{ml}$ groups was observed $(\mathrm{P}<0.001, \mathrm{P}=0.001, \mathrm{P}=0.001$ and $\mathrm{P}=0.001$, respectively). IL- 8 , interleukin-8; VEGF-D, vascular endothelial growth factor-D; VEGFR-3, vascular endothelial growth factor receptor-3; LECs, lymphatic endothelial cells; VEGF-C, vascular endothelial growth factor-C.

Table IV. Effect of IL-8 on LYVE-1, VEGF-D, VEGF-C and VEGFR-3 mRNA expression.

\begin{tabular}{lcccc}
\hline Group & LYVE-1 mRNA & VEGF-D mRNA & VEGF-C mRNA & VEGFR-3 mRNA \\
\hline Control & $1.01 \pm 0.17$ & $1.01 \pm 0.19$ & $1.00 \pm 0.03$ & $1.00 \pm 0.15$ \\
$0 \mathrm{ng} / \mathrm{ml}$ & $1.19 \pm 0.03$ & $0.62 \pm 0.12$ & $0.95 \pm 0.07$ & $1.66 \pm 0.11^{\mathrm{b}}$ \\
$0.2 \mathrm{ng} / \mathrm{ml}$ & $1.28 \pm 0.09$ & $0.58 \pm 0.06$ & $0.91 \pm 0.09$ & $1.24 \pm 0.04^{\mathrm{d}}$ \\
$0.5 \mathrm{ng} / \mathrm{ml}$ & $1.41 \pm 0.09^{\mathrm{c}}$ & $0.41 \pm 0.07^{\mathrm{c}}$ & $0.92 \pm 0.08$ & $1.33 \pm 0.05^{\mathrm{d}}$ \\
$0.8 \mathrm{ng} / \mathrm{ml}$ & $1.49 \pm 0.14^{\mathrm{d}}$ & $0.24 \pm 0.02^{\mathrm{d}}$ & $0.86 \pm 0.05$ & $1.32 \pm 0.04^{\mathrm{d}}$ \\
$1.0 \mathrm{ng} / \mathrm{ml}$ & $1.56 \pm 0.11^{\mathrm{d}}$ & $0.33 \pm 0.00^{\mathrm{d}}$ & $1.01 \pm 0.04$ & $1.36 \pm 0.13^{\mathrm{d}}$ \\
\hline
\end{tabular}

${ }^{\mathrm{a}} \mathrm{P}<0.05,{ }^{\mathrm{b}} \mathrm{P}<0.01 \mathrm{vs}$. control group, ${ }^{\mathrm{c}} \mathrm{P}<0.05,{ }^{\mathrm{d}} \mathrm{P}<0.01 \mathrm{vs}$. $0 \mathrm{ng} / \mathrm{ml}$ group. IL-8, interleukin- 8 ; LYVE-1, lymphatic vessel endothelial hyaluronic acid receptor-1; VEGF-D, vascular endothelial growth factor-D; VEGF-C, vascular endothelial growth factor-C; VEGFR-3, vascular endothelial growth factor receptor-3.
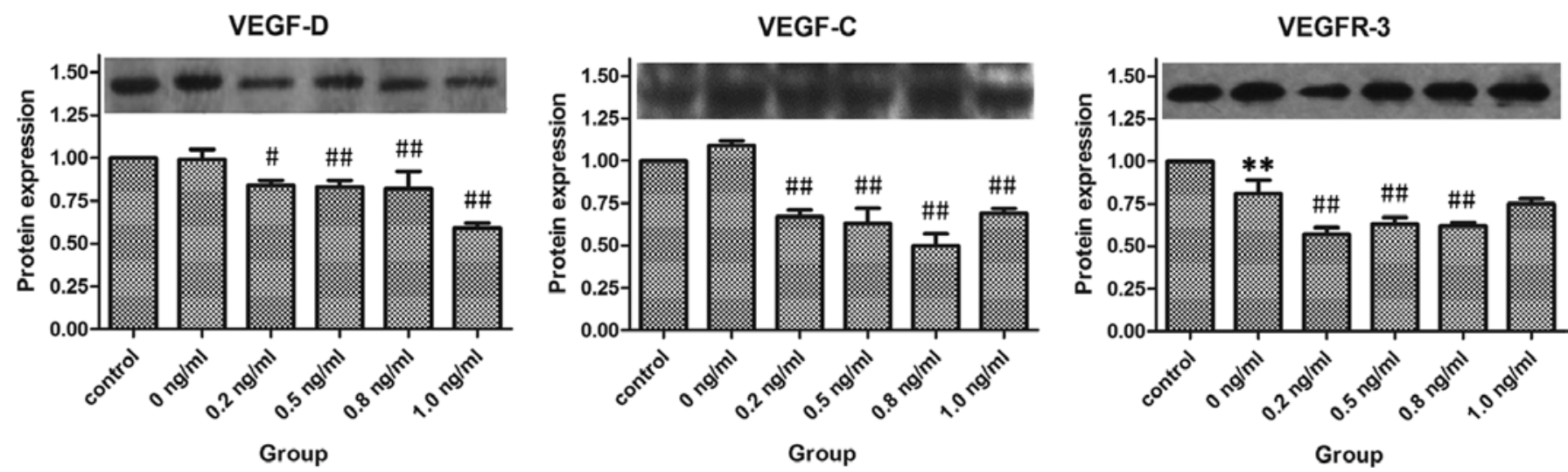

Figure 5. IL-8 inhibits VEGF-D, VEGF-C and VEGFR-3 protein expression in LECs (western blotting, VEGF-D 40 kDa, VEGF-C 80 kDa, VEGFR-3 $146 \mathrm{kDa}$ ). The VEGF-D and VEGF-C protein expression levels in the $0 \mathrm{ng} / \mathrm{ml}$ group showed a non-statistically significant difference compared with the control group ( $\mathrm{P}=0.817$ and $\mathrm{P}=0.259$, respectively). However, the VEGFR-3 protein expression was inhibited by pure SGC7901 cell culture medium ( $\mathrm{P}<0.001)$. The expression levels of VEGF-D in the $0.2,0.5,0.8$ and $1.0 \mathrm{ng} / \mathrm{ml}$ groups were all significantly decreased compared with the $0 \mathrm{ng} / \mathrm{ml}$ group $(\mathrm{P}=0.030, \mathrm{P}=0.002$, $\mathrm{P}=0.001$ and $\mathrm{P}<0.001$, respectively). A similar downregulated expression of the VEGF-C protein was observed (all $\mathrm{P}<0.001$ ). Meanwhile, VEGFR-3 expression levels in the $0.2,0.5$ and $0.8 \mathrm{ng} / \mathrm{ml}$ groups were significantly decreased compared with the $0 \mathrm{ng} / \mathrm{ml}$ group $(\mathrm{P}<0.001, \mathrm{P}=0.002$ and $\mathrm{P}=0.001$, respectively). ${ }^{* *} \mathrm{P}<0.01$ vs. control group; ${ }^{\#} \mathrm{P}<0.05,{ }^{\# /} \mathrm{P}<0.01$ vs. $0 \mathrm{ng} / \mathrm{ml}$ group. L-8, interleukin-8; VEGF-D, vascular endothelial growth factor-D; VEGF-C, vascular endothelial growth factor-C; VEGFR-3, vascular endothelial growth factor receptor-3; LECs, lymphatic endothelial cells.

nodes. It is credited with the transport of tissue fluids, extravasated plasma proteins and cells back into the blood circulation.
The lymphatic system is regarded as a fundamental route for cancer cell dissemination due to its initial lymphatic 
vessels larger than the blood capillaries, incomplete basement membrane and slower lymph flow than blood (23). Previous studies have found that lymphatic vessel density is correlated with the extent of lymph node metastasis (24-26). Meanwhile, expression of lymphangiogenic growth factors leads to formation of lymphatic vessels (24) and lymphatic metastasis can be blocked by inhibition of tumor lymphangiogenesis (27-29). Therefore, lymphangiogenesis is thought to play a pivotal role in cancer cells to format new lymphatic vessels and metastasis to the regional lymph nodes (30). In gastric cancer, lymphatic spread of tumor cells to regional lymph nodes is a common occurrence in the early stage (24,27). According to the American Joint Committee on Cancer (AJCC), lymph node metastasis of gastric cancer is one of the main prognostic factors; lymph node ratio has been proposed as a desirable predictor of survival (31). It has been revealed that lymphatic vessels refer to the spread of gastric cancer cells $(24,27)$, and human gastric adenocarcinoma organizes neighboring lymphatic vessels by inducing tumor lymphangiogenesis (32), which is thought to contribute actively to the development of lymphatic metastasis in gastric cancer (27-29).

The blood and lymphatic systems are similar in their function and anatomy; endothelial cells from blood and lymphatic systems were reported to have similar gene expression profiles (6-8). In a number of studies, various pro-inflammatory cytokines were found to indirectly induce both angiogenesis and lymphangiogenesis by activation of infiltrating immune cells to secrete many lymph or angiogenic factors (33). Although IL-8, a pro-inflammatory cytokine with a function in cancer development and metastasis (4), was one of the first CXC-cytokines identified to activate angiogenesis $(9,10)$, few studies have investigated its role in lymphangiogenesis. IL-8 was found to reduce post-surgical lymphedema formation by promoting lymphatic vessel regeneration via activation of lymphangiogenesis in vitro and in vivo. Notably, IL-8 directly promotes proliferation, tube formation and migration of cultured primary human LECs through its receptor CXCR2 (33). Mu et al revealed that IL-8 plays an important role in lysophosphatidic acid-induced lymphangiogenesis in vitro (34). In a study of prostate cancer xenografts, Sakai et al found that increased $\mathrm{Bcl}-2$ expression enhanced the expression and secretion of key lymphangiogenic factors and increased serum IL-8 contents, which correlated with increased angiogenic and lymphangiogenic levels in vivo (35). However, the direct role of IL-8 in lymphangiogenesis in gastric cancer has not been established. In the present study, we hypothesized that IL-8 plays a critical role in gastric cancer lymphangiogenesis. We investigated the growth of LECs cultured in gastric cancer SGC7901 cell culture medium supplemented with IL-8. We found that IL-8 promotes the growth of LECs, suggesting that IL-8 may be a direct promoter of lymphangiogenesis in gastric cancer.

The identification of lymphatic endothelial-specific biological markers has greatly increased attention to the regulation of lymphangiogenesis in the cancer microenvironment. LYVE-1, a homolog of the hyaluronan receptor $\mathrm{CD} 44$, is a type I integral membrane polypeptide expressed on the cell surface as a $60-\mathrm{kDa}$ protein. LYVE-1 is involved in hyaluronan metabolism in the lymphatic system where it transports hyaluronan from the extracellular matrix to lymph nodes $(36,37)$. To date, LYVE-1 is one of the most widely used marker for LECs in normal and cancer tissues. Indeed, LCEs are routinely identified by the expression of LYVE-1. Based on the enhanced growth of LECs, we investigated the effect of IL-8 on LYVE-1 protein and mRNA expression. Consistent with the proliferation of LECs, IL-8 promoted LYVE-1 protein and mRNA expression, confirming IL- 8 as a direct promoter of LECs.

The identification of vascular endothelial growth factors started with the discovery of VEGF-A in 1989 (38). To date, the VEGF family has been expanded to include VEGF-A, -B, -C, -D and -E and placental growth factor. VEGF-C not only stimulates mitosis and migration of endothelial cells, yet also increases vascular permeability. VEGF-D, structurally $48 \%$ identical to VEGF-C, is mitogenic to endothelial cells. Overexpression of VEGF-C/VEGF-D has been observed in a number of human types of cancers (25) and is involved in lymphatic hyperplasia $(36,37)$, lymphatic vessel invasion and/or lymph node metastasis (24). Macrophages in the peritumoral stroma produce VEGF-C and VEGF-D in certain cancers to induce lymphangiogenesis (39). Moreover, previous studies have shown that various inflammatory factors, such as IL-7, induce VEGF-D expression and promote lymphangiogenesis via the c-Fos/c-Jun pathway in lung cancer (40). Three VEGF tyrosine kinase receptors have been identified to date: VEGFR-1, VEGFR-2 and VEGFR-3; both VEGF-C and VEGF-D bind VEGFR-3, a tyrosine kinase receptor mainly involved in lymphangiogenesis where it controls the development and growth of the lymphatic system; thus, the VEGF-C/VEGF-D and VEGFR-3 signaling pathway has been shown to play a central role in lymphangiogenesis, and is widely used in studies of lymphangiogenic signaling $(24,25,27,41,42)$.

For gastric cancer, previous studies have indicated that the VEGF-C-VEGFR-3 signaling pathway plays a major role in lymphangiogenesis through both autocrine and paracrine mechanisms $(43,44)$, and quantitative analysis of VEGF-C and VEGFR-3 may be useful in predicting metastasis to regional lymph nodes $(30,45,46)$. The inhibition of VEGFR-3 phosphorylation is a therapeutic strategy for inhibiting lymph node metastasis of diffuse-type gastric cancer (47). However, the controversy remains as to whether VEGF-D is linked to lymphangiogenesis in gastric cancer. It was reported that both VEGF-C and VEGF-D enhanced lymphangiogenesis and neo-formation of lymphatic vessels in experimental gastric tumors via induction of VEGFR-3 expression (48). On the other hand, only the expression of VEGF-C (but not of VEGF-D) was significantly greater in gastric cancer patients with lymph node metastasis than in those without metastasis (49). We then investigated whether IL-8 promotes the growth of LECs by inducing the VEGF-C/VEGF-D and VEGFR-3 pathway. Notably. although enhanced growth of LECs and upregulated LYVE-1 expression were detected, VEGF-C, VEGF-D and VEGFR-3 were not upregulated and instead were inhibited by IL-8. Krzystek-Korpacka et al reported that elevation of circulating IL-8 was related to lymph node and distant metastases in esophageal squamous cell carcinomas, and circulating IL-8 correlated with lymphangiogenic VEGF-C rather than angiogenic VEGF-A. These findings suggested that IL-8 involvement in lymphatic 
spread may be indirect, with IL- 8 acting by stimulating VEGF-C expression and secretion (50). Notable, the present study did not support such a conclusion in gastric cancer. We showed a direct effect of IL-8 on the growth of LECs without stimulating VEGF-C expression. In a previous study of postsurgical lymphedema, Choi et al investigated the possible role of VEGF-C-VEGFR-3 signaling in IL-8-induced LEC proliferation using chemical inhibitors (Ki8751 and MAZ51) for VEGF receptors. They found that VEGF signaling did not play a role in IL-8-activated LEC proliferation (33). Our results are in agreement with these findings. Enhanced growth of LECs accompanied decreased VEGF-C, VEGF-D and VEGFR-3 expression after IL-8 addition. Although inflammatory factors (e.g. IL-7) were reported to induce VEGF-D upregulation and promote lymphangiogenesis (40), we could not demonstrate the involvement of VEGF-D-VEGFR-3 signaling in IL-8-induced LEC growth. The interaction between IL-8 and VEGF-C/VEGF-D-VEGFR-3 signaling pathway remains therefore unclear. We previously found that IL-8 induced downregulated expression of VEGF-C, VEGF-D and VEGFR-3. IL-8 is a multifunctional inflammatory cytokine released through the nuclear factor $(\mathrm{NF})-\kappa \mathrm{B}$ signaling pathway (51). Meanwhile, enhanced production of VEGF-C and VEGF-D was reported to be linked to NF- $\kappa \mathrm{B}$ activation in inflammatory lymphangiogenesis (52). Thus, we suppose that the IL-8-induced inhibition of VEGF-C, VEGF-D and VEGFR-3 may be associated with the NF- $\kappa \mathrm{B}$ signaling pathway. The mechanism of IL-8-induced lymphangiogenesis requires further investigation.

In conclusion, our data suggest IL-8 as a potent direct promoter of LEC growth in gastric cancer. However, this effect is not associated with VEGF-C/VEGF-D and VEGFR-3 signaling.

\section{Acknowledgements}

The present study was supported by a grant from the Three Year Action Plan Fund of Traditional Chinese Medicine, Shanghai City Health Administration, China (no. ZYSNXD-CCZDYJ024).

\section{References}

1. Ren Z, Pang G, Clancy R, Li LC, Lee CS, Batey R, Borody T and Dunkley M: Shift of the gastric T-cell response in gastric carcinoma. J Gastroenterol Hepatol 16: 142-148, 2001.

2. Kitadai Y, Haruma K, Mukaida N, Ohmoto Y, Matsutani N, Yasui W, Yamamoto S, Sumii K, Kajiyama G, Fidler IJ, et al: Regulation of disease-progression genes in human gastric carcinoma cells by interleukin 8. Clin Cancer Res 6: 2735-2740, 2000.

3. Kuai WX, Wang Q, Yang XZ, Zhao Y, Yu R and Tang XJ: Interleukin-8 associates with adhesion, migration, invasion and chemosensitivity of human gastric cancer cells. World J Gastroenterol 18: 979-985, 2012.

4. Waugh DJ and Wilson C: The interleukin- 8 pathway in cancer. Clin Cancer Res 14: 6735-6741, 2008.

5. Zhao ZS, Wang YY, Chu YQ, Ye ZY and Tao HQ: SPARC is associated with gastric cancer progression and poor survival of patients. Clin Cancer Res 16: 260-268, 2010.

6. Petrova TV, Mäkinen T, Mäkelä TP, Saarela J, Virtanen I, Ferrell RE, Finegold DN, Kerjaschki D, Ylä-Herttuala S and Alitalo K: Lymphatic endothelial reprogramming of vascular endothelial cells by the Prox-1 homeobox transcription factor EMBO J 21: 4593-4599, 2002.
7. Hirakawa S, Hong YK, Harvey N, Schacht V, Matsuda K, Libermann $T$ and Detmar M: Identification of vascular lineagespecific genes by transcriptional profiling of isolated blood vascular and lymphatic endothelial cells. Am J Pathol 162: 575-586, 2003.

8. Hong YK, Harvey N, Noh YH, Schacht V, Hirakawa S, Detmar M and Oliver G: Prox1 is a master control gene in the program specifying lymphatic endothelial cell fate. Dev Dyn 225: 351-357, 2002.

9. Koch AE, Polverini PJ, Kunkel SL, Harlow LA, DiPietro LA, Elner VM, Elner SG and Strieter RM: Interleukin-8 as a macrophage-derived mediator of angiogenesis. Science 258: 1798-1801, 1992.

10. Strieter RM, Kunkel SL, Elner VM, Martonyi CL, Koch AE, Polverini PJ and Elner SG: Interleukin-8. A corneal factor that induces neovascularization. Am J Pathol 141: 1279-1284, 1992.

11. Kim H, Kataru RP and Koh GY: Regulation and implications of inflammatory lymphangiogenesis. Trends Immunol 33: 350-356, 2012.

12. Bernaudin JF, Kambouchner M and Lacave R: Lymphatic vascular system, development and lymph formation. Review. Rev Pneumol Clin 69: 93-101, 2013 (In French).

13. Yu H, Zhang S, Zhang R and Zhang L: The role of VEGF-C/D and Flt-4 in the lymphatic metastasis of early-stage invasive cervical carcinoma. J Exp Clin Cancer Res 28: 98, 2009.

14. Harada A, Sekido N, Akahoshi T, Wada T, Mukaida N and Matsushima K: Essential involvement of interleukin-8 (IL-8) in acute inflammation. J Leukoc Biol 56: 559-564, 1994.

15. Raman D, Baugher PJ, Thu YM and Richmond A: Role of chemokines in tumor growth. Cancer Lett 256: 137-165, 2007.

16. Xie K: Interleukin- 8 and human cancer biology. Cytokine Growth Factor Rev 12: 375-391, 2001

17. Uemura $\mathrm{N}$, Okamoto $\mathrm{S}$, Yamamoto $\mathrm{S}$, Matsumura $\mathrm{N}$, Yamaguchi S, Yamakido M, Taniyama K, Sasaki N and Schlemper RJ: Helicobacter pylori infection and the development of gastric cancer. N Engl J Med 345: 784-789, 2001.

18. Correa P and Houghton J: Carcinogenesis of Helicobacter pylori. Gastroenterology 133: 659-672, 2007.

19. Crabtree JE, Farmery SM, Lindley IJ, Figura N, Peichl P and Tompkins DS: CagA/cytotoxic strains of Helicobacter pylori and interleukin-8 in gastric epithelial cell lines. J Clin Pathol 47: 945-950, 1994.

20. Sharma SA, Tummuru MK, Miller GG and Blaser MJ: Interleukin-8 response of gastric epithelial cell lines to Helicobacter pylori stimulation in vitro. Infect Immun 63: 1681-1687, 1995.

21. Campbell LM, Maxwell PJ and Waugh DJ: Rationale and means to target pro-inflammatory interleukin-8 (CXCL8) signaling in cancer. Pharmaceuticals 6: 929-959, 2013.

22. Ju D, Sun D, Xiu L, Meng X, Zhang C and Wei P: Interleukin- 8 is associated with adhesion, migration and invasion in human gastric cancer SCG-7901 cells. Med Oncol 29: 91-99, 2012.

23. Scavelli C, Weber E, Aglianò M, Cirulli T, Nico B, Vacca A and Ribatti D: Lymphatics at the crossroads of angiogenesis and lymphangiogenesis. J Anat 204: 433-449, 2004.

24. Achen MG and Stacker SA: Tumor lymphangiogenesis and metastatic spread - new players begin to emerge. Int J Cancer 119: 1755-1760, 2006.

25. Pepper MS, Tille JC, Nisato R and Skobe M: Lymphangiogenesis and tumor metastasis. Cell Tissue Res 314: 167-177, 2003.

26. Nakamura Y, Yasuoka $H$, Tsujimoto $M$, Kurozumi K, Nakahara M, Nakao K and Kakudo K: Importance of lymph vessels in gastric cancer: A prognostic indicator in general and a predictor for lymph node metastasis in early stage cancer. J Clin Pathol 59: 77-82, 2006.

27. Alitalo K, Tammela T and Petrova TV: Lymphangiogenesis in development and human disease. Nature 438: 946-953, 2005.

28. Achen MG, McColl BK and Stacker SA: Focus on lymphangiogenesis in tumor metastasis. Cancer Cell 7: 121-127, 2005.

29. Shimizu K, Kubo H, Yamaguchi K, Kawashima K, Ueda Y, Matsuo K, Awane M, Shimahara Y, Takabayashi A, Yamaoka Y, et al: Suppression of VEGFR-3 signaling inhibits lymph node metastasis in gastric cancer. Cancer Sci 95: 328-333, 2004.

30. Al-Rawi MA and Jiang WG: Lymphangiogenesis and cancer metastasis. Front Biosci 16: 723-739, 2011.

31. Medina-Franco H, Cabrera-Mendoza F, Almaguer-Rosales S, Guillén F, Suárez-Bobadilla YL and Sánchez-Ramón A: Lymph node ratio as a predictor of survival in gastric carcinoma. Am Surg 79: 284-289, 2013. 
32. Tawada M, Hayashi S, Osada S, Nakashima S and Yoshida K Human gastric cancer organizes neighboring lymphatic vessels via recruitment of bone marrow-derived lymphatic endothelial progenitor cells. J Gastroenterol 47: 1057-1060, 2012.

33. Choi I, Lee YS, Chung HK, Choi D, Ecoiffier T, Lee HN, Kim KE, Lee S, Park EK, Maeng YS, et al: Interleukin-8 reduces post-surgical lymphedema formation by promoting lymphatic vessel regeneration. Angiogenesis 16: 29-44, 2013.

34. Mu H, Calderone TL, Davies MA, Prieto VG, Wang H, Mills GB, Bar-Eli M and Gershenwald JE: Lysophosphatidic acid induces lymphangiogenesis and IL-8 production in vitro in human lymphatic endothelial cells. Am J Pathol 180: 2170-2181, 2012.

35. Sakai Y, Goodison S, Kusmartsev S, Fletcher B, Eruslanov E, Cao W, Porvasnik S, Namiki K, Anai S and Rosser CJ: Bcl-2 mediated modulation of vascularization in prostate cancer xenografts. Prostate 69: 459-470, 2009.

36. Al-Rawi MA, Mansel RE and Jiang WG: Molecular and cellular mechanisms of lymphangiogenesis. Eur J Surg Oncol 31: 117-121, 2005.

37. Platonova N, Miquel G, Regenfuss B, Taouji S, Cursiefen C, Chevet $\mathrm{E}$ and Bikfalvi A: Evidence for the interaction of fibroblast growth factor-2 with the lymphatic endothelial cell marker LYVE-1. Blood 121: 1229-1237, 2013.

38. Leung DW, Cachianes G, Kuang WJ, Goeddel DV and Ferrara N: Vascular endothelial growth factor is a secreted angiogenic mitogen. Science 246: 1306-1309, 1989.

39. Schoppmann SF, Birner P, Stöck1 J, Kalt R, Ullrich R Caucig C, Kriehuber E, Nagy K, Alitalo K and Kerjaschki D: Tumor-associated macrophages express lymphatic endothelial growth factors and are related to peritumoral lymphangiogenesis. Am J Pathol 161: 947-956, 2002.

40. Ming J, Zhang Q, Qiu X and Wang E: Interleukin 7/interleukin 7 receptor induce c-Fos/c-Jun-dependent vascular endothelial growth factor-D up-regulation: A mechanism of lymphangiogenesis in lung cancer. Eur J Cancer 45: 866-873, 2009.

41. Matsumoto M, Roufail S, Inder R, Caesar C, Karnezis T, Shayan R, Farnsworth RH, Sato T, Achen MG, Mann GB, et al: Signaling for lymphangiogenesis via VEGFR-3 is required for the early events of metastasis. Clin Exp Metastasis 30: 819-832, 2013.

42. Ji RC: Lymph node lymphangiogenesis: A new concept for modulating tumor metastasis and inflammatory process. Histol Histopathol 24: 377-384, 2009.

43. Matsumura S, Oue N, Mitani Y, Kitadai Y and Yasui W: DNA demethylation of vascular endothelial growth factor- $\mathrm{C}$ is associated with gene expression and its possible involvement of lymphangiogenesis in gastric cancer. Int J Cancer 120: 1689-1695, 2007.
44. Kodama M, Kitadai Y, Tanaka M, Kuwai T, Tanaka S, Oue N, Yasui $\mathrm{W}$ and Chayama K: Vascular endothelial growth factor $\mathrm{C}$ stimulates progression of human gastric cancer via both autocrine and paracrine mechanisms. Clin Cancer Res 14: 7205-7214, 2008.

45. Yuanming L, Feng G, Lei T and Ying W: Quantitative analysis of lymphangiogenic markers in human gastroenteric tumor. Arch Med Res 38: 106-112, 2007.

46. Zhu P, Zhang J, Chen Q, Wang J and Wang Y: Expression of vascular endothelial growth factor- $\mathrm{C}$ in gastric carcinoma and the effect of its antisense gene transfection on the proliferation of human gastric cancer cell line SGC-7901. Am J Surg 204: 78-83, 2012.

47. Yashiro M, Shinto O, Nakamura K, Tendo M, Matsuoka T, Matsuzaki T, Kaizaki R, Ohira M, Miwa A and Hirakawa K: Effects of VEGFR-3 phosphorylation inhibitor on lymph node metastasis in an orthotopic diffuse-type gastric carcinoma model. Br J Cancer 101: 1100-1106, 2009.

48. Yonemura Y, Endo Y, Tabata K, Kawamura T, Yun HY, Bandou E, Sasaki $\mathrm{T}$ and Miura M: Role of VEGF-C and VEGF-D in lymphangiogenesis in gastric cancer. Int J Clin Oncol 10: 318-327, 2005.

49. Kitadai Y, Kodama M, Cho S, Kuroda T, Ochiumi T, Kimura S, Tanaka S, Matsumura S, Yasui W and Chayama K: Quantitative analysis of lymphangiogenic markers for predicting metastasis of human gastric carcinoma to lymph nodes. Int J Cancer 115: 388-392, 2005

50. Krzystek-Korpacka M, Matusiewicz M, Diakowska D, Grabowski K, Blachut K, Konieczny D, Kustrzeba-Wojcicka I, Terlecki G and Banas T: Elevation of circulating interleukin-8 is related to lymph node and distant metastases in esophageal squamous cell carcinomas - implication for clinical evaluation of cancer patient. Cytokine 41: 232-239, 2008.

51. Sharma SA, Tummuru MK, Blaser MJ and Kerr LD: Activation of IL-8 gene expression by Helicobacter pylori is regulated by transcription factor nuclear factor-kappa B in gastric epithelial cells. J Immunol 160: 2401-2407, 1998

52. Watari K, Nakao S, Fotovati A, Basaki Y, Hosoi F, Bereczky B, Higuchi R, Miyamoto T, Kuwano $M$ and Ono M: Role of macrophages in inflammatory lymphangiogenesis: Enhanced production of vascular endothelial growth factor $\mathrm{C}$ and $\mathrm{D}$ through NF-kappaB activation. Biochem Biophys Res Commun 377: 826-831, 2008. 